\title{
Deflection Prediction of No-Fines Lightweight Concrete Wall Using Neural Network Caused Dynamic Loads
}

\author{
Ridho Bayuaji ${ }^{1, *}$ and Totok Ruki Biyanto ${ }^{2}$ \\ 1 Department of Civil Infrastructure Engineering, Faculty of Vocations, Institut Teknologi Sepuluh Nopember, \\ Surabaya 60116, Indonesia \\ 2 Department of Engineering Physic, Faculty of Industrial Technologi, Institut Teknologi Sepuluh Nopember, \\ Surabaya 60116, Indonesia; trbiyanto@gmail.com \\ * Correspondence: bayuaji@ce.its.ac.id; Tel.: +62-31-594-7637
}

Received: 19 March 2018; Accepted: 17 April 2018; Published: 23 April 2018

check for updates

\begin{abstract}
No-fines lightweight concrete wall with horizontal reinforcement refers to an alternative material for wall construction with an aim of improving the wall quality towards horizontal loads. This study is focused on artificial neural network (ANN) application to predicting the deflection deformation caused by dynamic loads. The ANN method is able to capture the complex interactions among input/output variables in a system without any knowledge of interaction nature and without any explicit assumption to model form. This paper explains the existing data research, data selection and process of ANN modelling training process and validation. The results of this research show that the deformation can be predicted more accurately, simply and quickly due to the alternating horizontal loads.
\end{abstract}

Keywords: wall; hysteresis; dynamic; no-fines lightweight concrete; artificial neural network

\section{Introduction}

Indonesian territory is prone to earthquake disasters occurring as a consequence of its position. As it is the point of the interaction of four tectonic plates, including Australian, Eurasian, Pacific, and Philippine, moreover, it is the place in which two primary earthquake courses (Circum-Pacific Earthquake Belt and Trans Asiatic Earthquake Belt) pass through. Over the last five decades, dozens of large earthquakes occurred in Indonesia and they have led to many casualties. It is worth noting here that even the conventional force-based seismic design approach is strongly connected to the deformation capacity parameter through the force-reduction factor which is used in the estimation of design force of structures in the force-based seismic design approach. Furthermore, the deformation capacity plays a crucial role in seismic assessment and retrofitting of existing structures, which has become one of the main research topics in structural engineering.

This phenomenon can be minimized through awareness of unreinforced masonry building, even for the non-engineered building construction. A simple house construction commonly uses a brick masonry wall which, when a horizontal force (earthquake) occurs, can lead to total and immediate collapse starting from the damage and the collapse in the part of masonry wall followed by other building structures. This happens since the masonry wall in a simple house is used as a structural part supporting the lateral loads (limited friction) due to the earthquake load. Seismic behaviour of masonry walls was specifically discussed for its shear capacity drives in several papers [1,2].

The displacement capacity is a key parameter in the seismic design and assessment of structures. Unfortunately, our current state of knowledge of the displacement capacity of masonry walls is limited. On the one hand, the available experimental data has pronounced variability, so it is not possible to identify rational values for the displacement capacity of masonry walls based only on 
such experimental data and, on the other hand, there are no reliable analytical models for either the displacement capacity or the force-displacement relationship of masonry walls [3].

In general, the displacement capacity of masonry walls is a very complex value; it is influenced not only by the failure mode but also by many other factors such as the constituent materials, geometry, boundary conditions, and pre-compression level. Currently, we are still not able to take into account properly the influences of all factors affecting the displacement capacity of masonry walls due to inhomogeneous experimental data and a lack of reliable analytical models.

The assessment of the nonlinear seismic behaviour of masonry walls represents a subject of great importance, however it is rather difficult to solve.

The behavior of unreinforced masonry wall panels subject to dynamic excitation such as seismic loading is very complex and - up to today-not yet entirely investigated and understood. There are neither instructions for the determination of the seismic input onto the wall nor a concept for the approximation of the dynamic stability leaving it up to the structural engineer to find a practicable method for the seismic verification. Quite often the seismic input is hence determined by using the definition for non-structural components that may be an acceptable approximation in many cases. However, there are no guidelines specifically for vital non-structural components and for components that represent a potential risk. Including a seismic verification using a realistic model and realistic response spectra that take into account the filtering effects of the structure is required. They are not explained clearly by Eurocode 8 [4].

The deformation occurring under lateral loading on unreinforced masonry wall was explained Bourzam [5] which the element's stiffness depends on the mechanical properties of constituent material, the geometry and boundary conditions. When subjected to a lateral load $\mathrm{V}$, a confined masonry wall generates a horizontal deflection $\delta$. This lateral displacement is the sum of the deflection due to flexure and the deformation due to shear as defined in the Equations (1)-(5). The detail correlation lateral load (V) and horizontal deflection as deformation of unreinforced masonry wall under lateral loading is figured on Figure 1.

$$
\begin{gathered}
\delta=\frac{V h^{3}}{\alpha E_{e q v} I_{w}}+\frac{1.2 V h}{G_{e q v} A_{w}} \\
V=K_{e} \delta
\end{gathered}
$$

where:

$K_{e}=$ the effective stiffness of confined wall

$I_{w}=\mathrm{tl}^{3} / 12$, moment inertia of the wall's cross section

$A_{w}=$ area of the wall's horizontal

$1.2=$ the shear coefficient for rectangular cross-section

$\alpha=$ coefficient depends on the boundary condition, $\alpha=3$ for cantilever panel and $\alpha=12$ in case of fixed-ended wall

$E_{\text {Equation }}=$ modulus of elasticity equivalent

$G_{\text {Equation }}=$ shear modulus equivalent

$$
\begin{aligned}
E_{\text {eqv }} & =\frac{E_{m} A_{m}+2 E_{c} A_{c}}{A_{m}+2 A_{c}} \\
G_{\text {eqv }} & =\frac{G_{m} A_{m}+2 G_{c} A_{c}}{A_{m}+2 A_{c}}
\end{aligned}
$$

After substituting the value of $\mathrm{V}$ from Equation (2) into Equation (1) and rearranging its different terms, the general equation for the effective stiffness of confined masonry wall in the elastic domain is obtained and expressed as follows: 


$$
K_{e}=\frac{G_{e q v} A_{w}}{1.2 h\left[1+\mu \frac{G_{e q v}}{E_{e q v}}\left(\frac{h}{l}\right)^{2}\right]}
$$

$\mu=$ coefficient describes the applied restraint conditions of the wall, $\mu=3.33$ for cantilever walls and $\mu=0.83$ in case of fixed-ended walls.

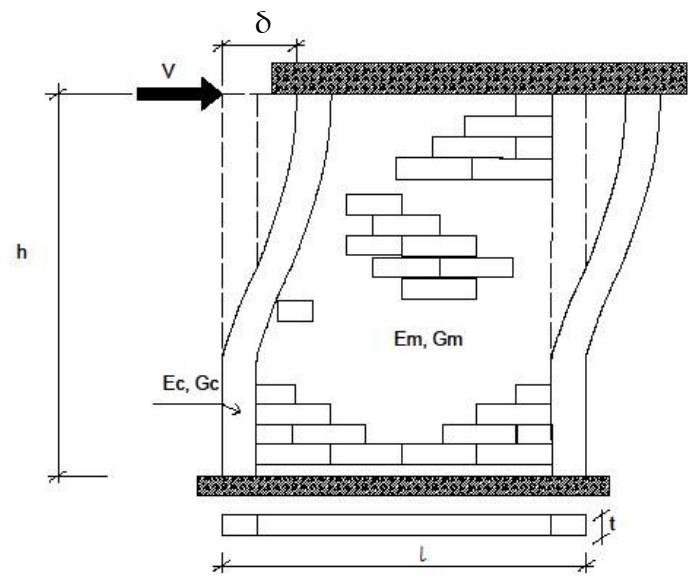

Figure 1. Deformation of unreinforced masonry wall under lateral loading.

This clearly shows that further research into this field of seismic engineering is inevitable. The outcome of the research should be a new verification concept that allows for a quick and easy verification based on limit values and also provides guidance for a more advanced investigation of the dynamic stability using displacement-based approaches. It is interesting to observe the model of an artificial neural network [6-9] of dynamic capacity of no-fines lightweight concrete wall with or without any horizontal reinforcement. As the name implies, no-fines lightweight concrete is a conventional lightweight concrete which eliminates the engagement of fine aggregate, in order to achieve some advantages. For example, it won't segregate and is cheap.

Modelling with an artificial neural network (ANN) [10] refers to the Black Box modelling in which the input is installed with a proper output. This model consists of connections and processing elements (neurons).

In common, the structure of the ANN is multilayer perceptron (MLP). Figure 2 illustrates the MLP structure consisting of input, hidden and output layer.

Cybenko [11] explained that the ANN model using the function of tangent hyperbolic activation in a hidden layer and linear function in its layer output is able to predict the accuracy of all modelled systems. Because of that, Equations (6)-(19) used to arrange the ANN modelling.

To determine the weight, for example by connecting $\hat{y}_{i}$ output to $\varphi_{i}$ input, needs an attempt called training/learning. In training, the weight is adjusted to obtain the network output suitable with the process or target output. This learning algorithm will continuously adjust the weight until the target desired is reached. MLP can be written mathematically as follows:

$$
y_{i}=F_{i}\left[\sum_{j=1}^{n_{h}} W_{i, j} \cdot f_{j}\left(\sum_{l=1}^{n_{\phi}} w_{j, l} \phi_{l}+w_{j, 0}\right)+W_{i, 0}\right]
$$

The learning algorithm used in this research was Levenberg Marquardt Algorithm. Though being more complex in comparison with the back-propagation algorithm, this algorithm is able to provide a better result. The derivation of this algorithm can be seen in Norgaard [12] and can be explained as follows. 


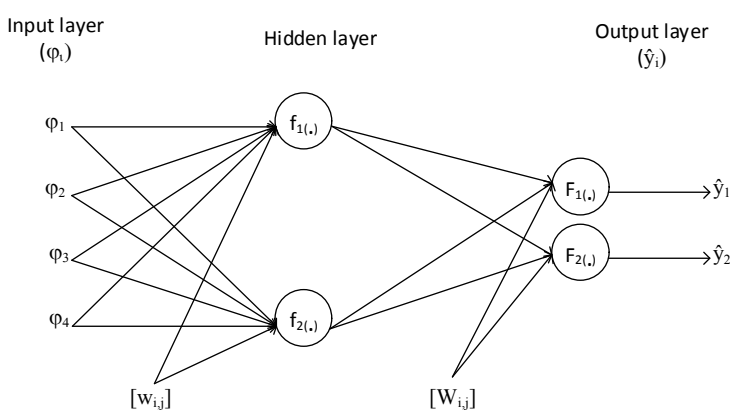

Figure 2. Structure of multilayer perceptron.

Training Data refers to a set of inputs $u(k)$ paired with the desired output of $y(k)$ as given below:

$$
Z^{N}=\{[u(k), y(k)] \mid k=1, \ldots, N\}
$$

The objective of this learning is to determine the weight that might be from the data pair given.

$$
Z^{N} \rightarrow w
$$

Thus, the network can result in an estimation of output of $y(k)$ that is equal or closer to the output of $y(k)$. The error estimation will be approached using mean square error criterion:

$$
\begin{aligned}
& V_{N}\left(w, Z^{N}\right)=L^{(i)}(w) \\
& =\frac{1}{2 N} \sum[y(k)-\hat{y}(k \mid w)]^{T}[y(k)-\hat{y}(k \mid w]
\end{aligned}
$$

The weight obtained:

$$
\begin{gathered}
w=\arg \min _{w} V_{N}\left(w, Z^{N}\right) \\
w^{(i+1)}=w^{(i)}+\mu^{(i)} f^{(i)}
\end{gathered}
$$

$w^{i}$ refers to the recent weight, $f^{(i)}$ denotes the direction of searching and $\mu^{(i)}$ is the extent of step. Levenberg Marquardt is a standard method for the minimization of mean square error criterion. This algorithm has $\lambda$ parameter to maintain convergence. The value of $\lambda$ is controlled by the ratio between the decrease of actual value and the prediction value.

$$
r^{(i)}=\frac{V_{N}\left(w^{(i)}, Z^{N}\right)-V_{N}\left(w^{(i)}+f^{(i)}, Z^{N}\right)}{V_{N}\left(w^{(i)}, Z^{N}\right)-L^{(i)}\left(w^{(i)}+f^{(i)}\right)}
$$

where:

$$
L\left(w^{(i)}+f\right)=\sum_{k=1}^{N}\left(y(k)-\hat{y}(k \mid w)-f^{T} \frac{\partial \hat{y}(k \mid w)}{\partial w}\right)^{2}=V_{N}\left(w^{(i)}, Z^{N}\right)+f^{T} G\left(w^{(i)}\right)+\frac{1}{2} f^{T} R\left(w^{(i)} f\right.
$$

G shows a gradient of criteria by referring to the weight and $\mathrm{R}$ refers to the approach of Hessian. If the ratio gets closer to one, $L(i)\left(w^{(i)}+f\right)$ approaches $V_{N}$, and $\lambda$ should be reduced through some factors. Conversely, if the ratio is little or negative, $\lambda$ should be added. The Levenberg Marquardt algorithm can be summarized as follows.

1. Select the vector of initial weight of $w^{(0)}$ and the initial value of $\lambda^{(0)}$ where $w$ refers to the weight and $\lambda$ is given the initial value.

2. Determine the direction of searching in which I refers to the matrix of identity.

$$
\left[R\left(w^{(i)}+\lambda^{(i)} I\right] f^{(i)}=-G\left(w^{(i)}\right)\right.
$$


Thus, $f$ is obtained and put into

$$
\begin{gathered}
w=\arg \min _{w} V_{N}\left(w, Z^{N}\right) \\
w^{(i+1)}=w^{(i)}+\mu^{(i)} f^{(i)}
\end{gathered}
$$

If the objective function in the current iteration is less than the previous iteration or $V_{N}\left(w^{(i)}+\right.$ $\left.f^{(i)}, Z^{N}\right)<V^{N}\left(w^{(i)}, Z^{N}\right)$; thus, the current weight has been added to be a new weight $w^{(i+1)}=w^{(i)}+f^{(i)}$. For this, the new searching direction of searching is the old searching direction $\lambda^{(i+1)}=\lambda^{(i)}$. If not, finding new $\lambda$ must be found from the $r$ value.

$$
r^{(i)}=\frac{V_{N}\left(w^{(i)}, Z^{N}\right)-V_{N}\left(w^{(i)}+f^{(i)}, Z^{N}\right)}{V_{N}\left(w^{(i)}, Z^{N}\right)-L^{(i)}\left(w^{(i)}+f^{(i)}\right)}
$$

If $r^{(i)}>0.75$ thus $\lambda^{(i)}=\lambda^{(i)} / 2$.

If $r^{(i)}<0.25$ thus $\lambda^{(i)}=2 \lambda^{(i)}$.

where $V$ is calculated from the equation of Levenberg Marquard $L$

$$
\begin{gathered}
V_{N}\left(w, Z^{N}\right)=L^{(i)}(w) \\
=\frac{1}{2 N} \sum[y(k)-\hat{y}(k \mid w)]^{T}[y(k)-\hat{y}(k \mid w] \\
L^{(i)}\left(w^{(i)}+f^{(i)}\right)=\left(\lambda^{(i)} f^{(i) \mathrm{T}} f^{(i)}\right)-\left(f^{(i) \mathrm{T}} \mathrm{G}\right)
\end{gathered}
$$

3. If the criteria are achieved, the calculation is terminated. Conversely, if the criteria are not achieved yet, it must be started from step 2 .

\section{Research Method}

Table 1 shows the specimen of no-fines lightweight concrete wall was made into 2 (two) variations: no-fines lightweight concrete wall without horizontal reinforcement (lightweight concrete wall, LCW) and no-fines lightweight concrete wall with horizontal reinforcement with $6 \mathrm{~mm}$-diameter with the distance of 200-mm inter-reinforcements (lightweight concrete wall with horizontal bars, LCWHB-200) as shown in Figures 3 and 4.

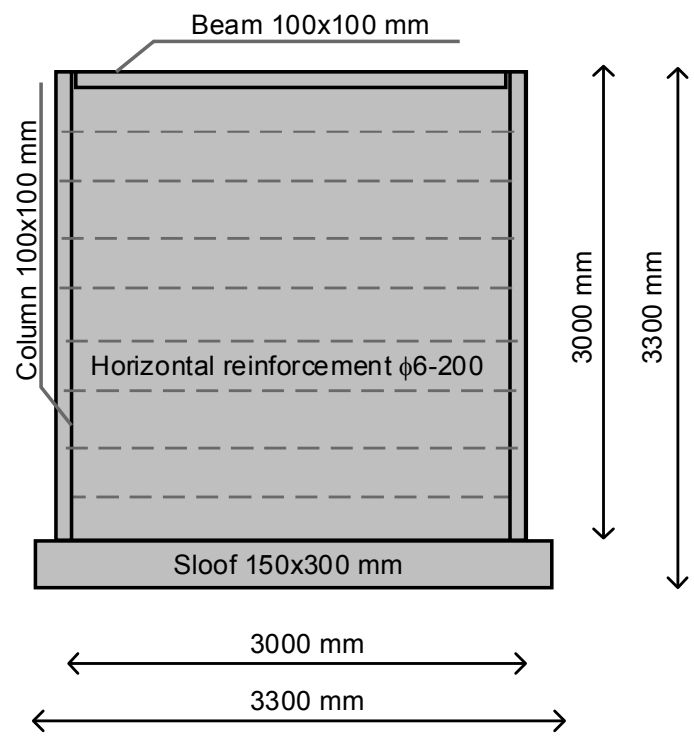

Figure 3. LCWHB-200. 


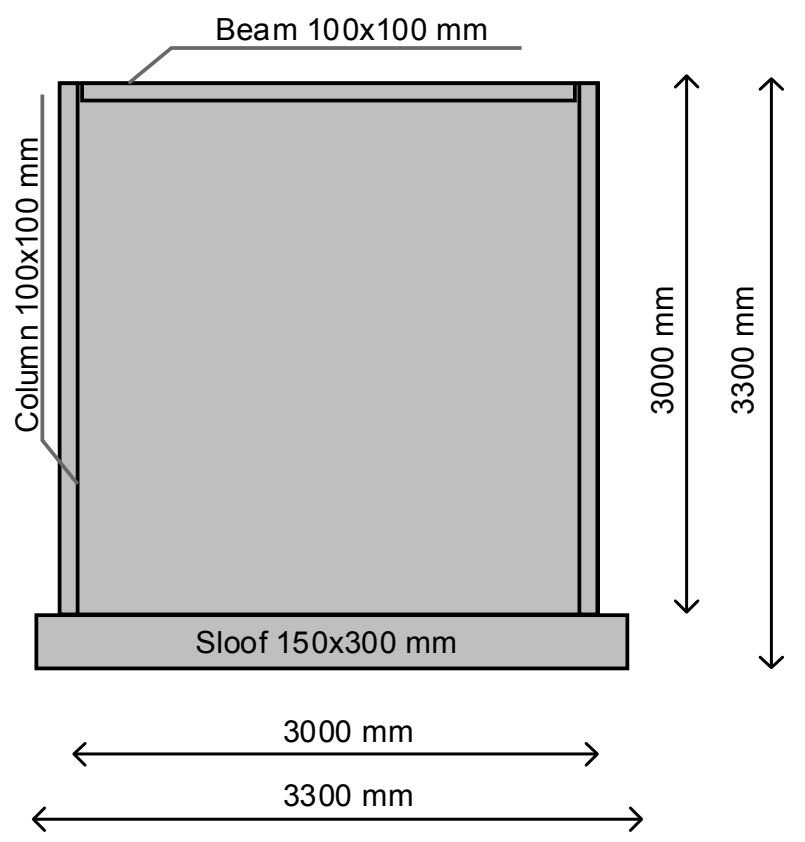

Figure 4. LCW.

Table 1. Dimension of the specimen of no-fine lightweight concrete wall.

\begin{tabular}{cccc}
\hline \multicolumn{2}{c}{ Code } & LCW & LCWHB-200 \\
\hline Size $(\mathrm{mm})$ & Column & $100 \times 100$ & $100 \times 100$ \\
\cline { 2 - 4 } & Beam & $100 \times 100$ & $100 \times 100$ \\
\hline $\begin{array}{c}\text { Number of Steel } \\
\text { reinforcements }\end{array}$ & $4 \varnothing 8$ & $4 \varnothing 8$ \\
\hline Confinement distance & $\varnothing 6-150$ & $\varnothing 6-150$ \\
\hline Horizontal reinforcement & - & $\varnothing 6-200$ \\
\hline
\end{tabular}

The constituent materials of no-fines lightweight concrete wall in this research was structured from the binding material of 50-kg Portland cement type I (Indocement), PDAM water at Structure Laboratory, Department of Civil Engineering of Gadjah Mada University, 10-20 mm diameter aggregate originated from Kemiri Village, Pakem Sleman. PDAM has acronym Perusahaan Daerah Air Minum, Indonesia regional water utility company. In addition, the reinforcement steel used in forming the reinforced concrete frame was the ISPAT steel, the company was set up as a 60,000 tpa Greenfield project, for rolling from Surabaya with $8-\mathrm{mm}$ plain steel reinforcement (fy $=341.62 \mathrm{MPa}$ ) as the column reinforcement and practical beam. The 6-mm reinforcement (fy $=263.06 \mathrm{MPa}$ ) was used as the shear reinforcing and horizontal reinforcement on the wall. The no-fines lightweight concrete wall was planned with the stress force on the average of $4.45 \mathrm{Mpa}$, elasticity modulus on the average of $1632.75 \mathrm{Mpa}$, splitting tensile was on the average of $0.248 \mathrm{Mpa}$, and adhesive reinforcement in no-fine concrete at $1.661 \mathrm{Mpa}$ (34.62\% of the adhesive reinforcement in normal concrete). No-fines lightweight concrete has a weight of $1572 \mathrm{kN} / \mathrm{m}^{2}, 94.3 \%$ lower than the red brick. The ready-mix normal concrete with $\mathrm{fc}^{\prime}=25.90 \mathrm{MPa}$ for sloof beam with the ratio of Portland Cement:Sand:Coarse Aggregate = 1:2:3.

The equipment used in the research is included loading frame, load cell, crane, rigid floor, hydraulic jack and hydraulic pump machine with the capacity of 50 tons, data lodger, and computer. 6 units of 50-mm Linear Variable Differential Transformer (LVDT) with the accuracy of $0.01 \mathrm{~mm}$ and all was connected to data lodger were used to measure the level of deflection. Set up of the test on those three specimens can be seen in Figure 5. 


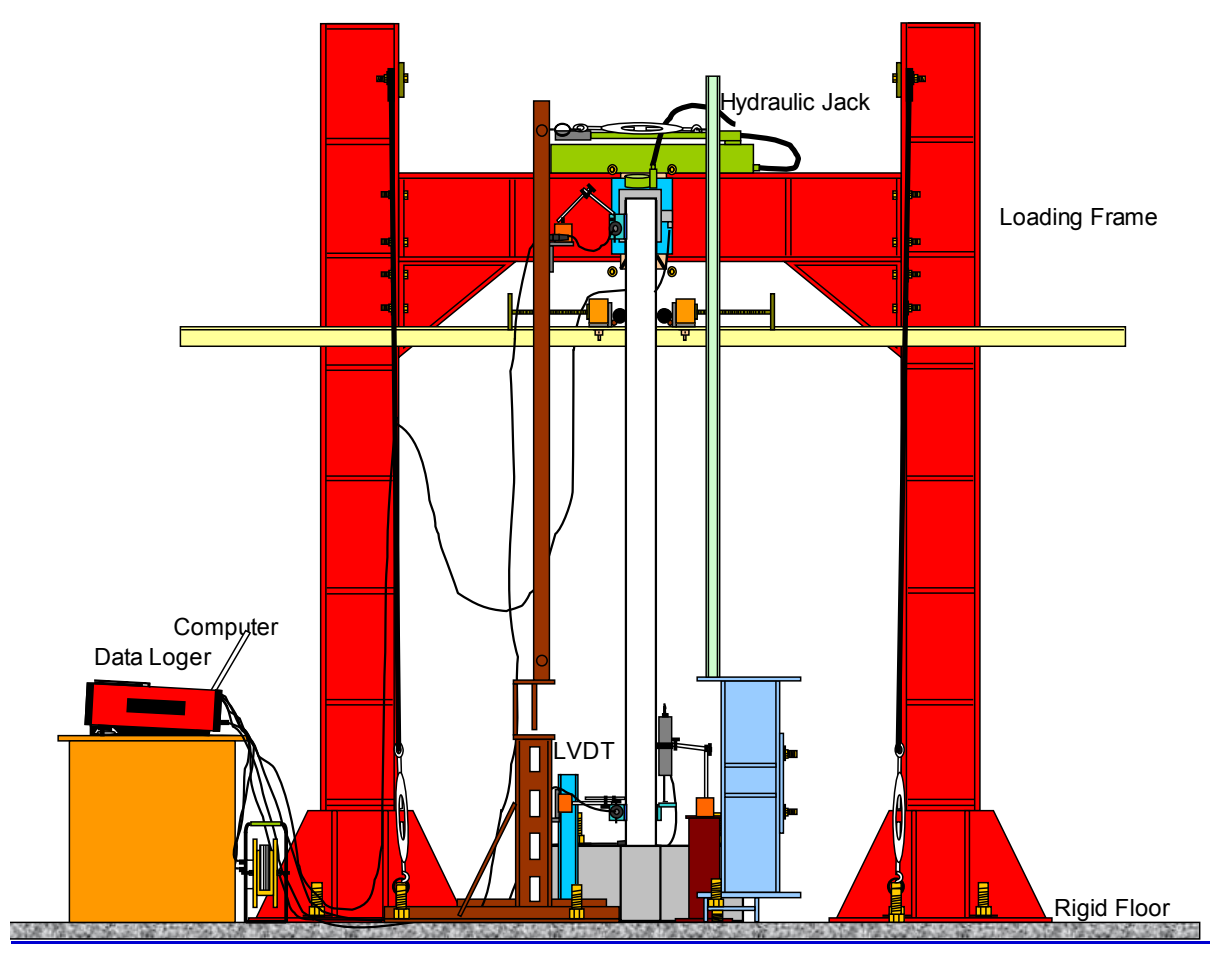

Figure 5. Test Setting.

Cyclic lateral load was given as unidirectional with the axis of wall strength referring to American Society for Testing Materials (ASTM) E 2126-02a Method B (amplitudes of the Reversed Cycles). The lateral load was given to the specimen with alternating direction until reaching the yield in which it was then continued to reach a collapse (failure) and loading was based on the displacement control.

Meanwhile, data obtained from the test above was used to make an ANN-based model that can be used to predict the horizontal deflection by entering the input condition that would be predicted. ANN will predict in an interpolation and extrapolation of horizontal deflection. Here, the model of ANN proposed to predict the horizontal deflection (force and deviation) was developed by means of MATLAB R2013 (TechSource Systems Pte Ltd, Singapore) MATLAB 7.1. Figure 6 presents the structure of the artificial neural network model in which the force was the input data and deflection was the output.

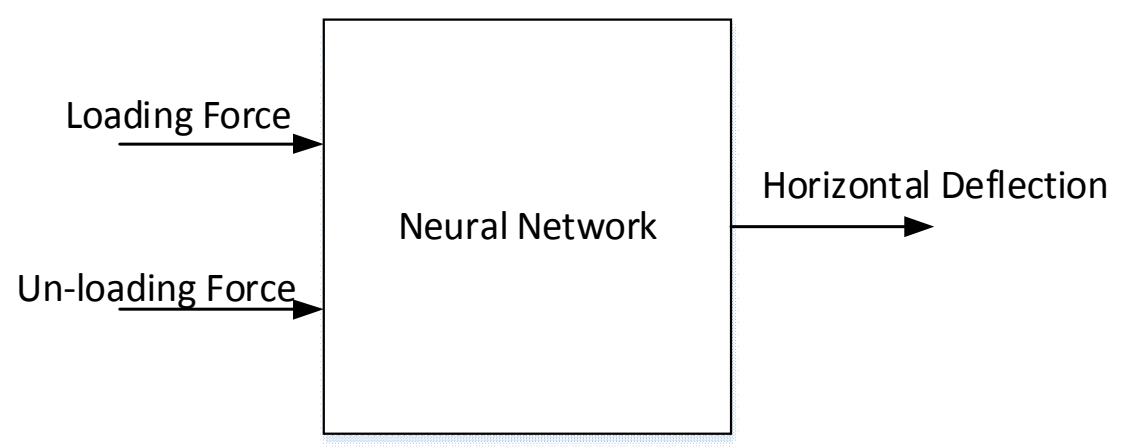

Figure 6. The Proposed model of artificial neural network (ANN) for the force and deflection.

\section{Results and Analysis}

This neural network model used a FIR (Finite Impulse Response) structure. It was characterized by placing the variable of input model from the input itself. The input data used in this study was 
1217 data points for the no-fines lightweight concrete wall without the horizontal reinforcement unreinforced and 2688 data points for the no-fines lightweight concrete wall with the horizontal reinforcement unreinforced. The equation, Equation (20) of model output can be presented as follows:

$$
\hat{Y}=f\left(U_{1}, U_{2}, U_{3}\right)
$$

The artificial neural network model of the no-fines lightweight concrete used MLP; trained by Marquardt algorithm conducted in 200 iterations. The neural model was trained with training data to determine the weight value. Then, the weight used for the validation of neural models by using other input and output data. The goodness of system identification was measured by using Equation (21), Root Mean Square Error (RMSE), which can be written as follows:

$$
R M S E=\sqrt{\frac{\sum_{i=1}^{N}\left(y_{i}-\hat{y}_{i}\right)^{2}}{N}}
$$

The best RMSE obtained from the no-fines lightweight concrete with the reinforcement was at 0.2629 for training and at 0.7701 for validation. Meanwhile, the best RMSE obtained in the no-fines lightweight concrete wall without reinforcement was at 0.0431 for training and at 0.0462 for validation. The trained neural network model was also validated in a set of data that was not used for network training (Figures 7 and 8). Using fixed values of the weights that obtained in training phase, the neural networks should produce the predicted output from the new input data. Figure 9 and 10 illustrate the validation phase.

These results confirm that no-fines lightweight concrete with the reinforcement provides better results than without bar steel horizontal. The mechanical properties of horizontal reinforcement improved the strength behavior of no-fine lightweight concrete as the wall element. This is shown in the RMSE results and images on training and validation. Figure 7 shows the training for no-fines lightweight concrete wall with the horizontal reinforcement showing a more orderly and non-random pattern, as well as Figure 9 as a validation image showing similar trends. These are different with Figures 8 and 10. They were figured as training and validation for no-fines lightweight concrete without the reinforcement.

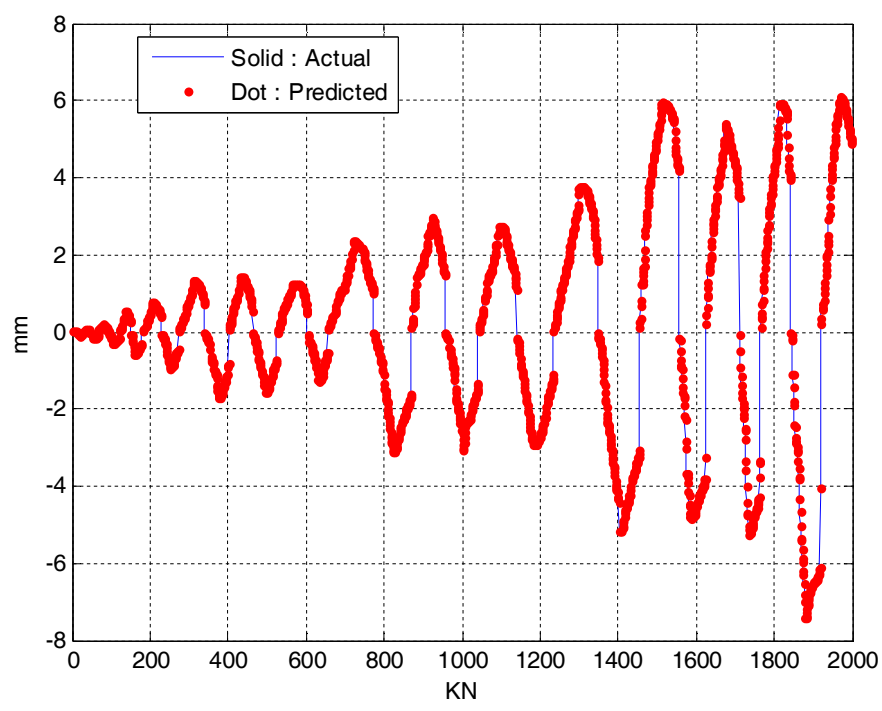

Figure 7. Training for no-fines lightweight concrete wall with the horizontal reinforcement. 


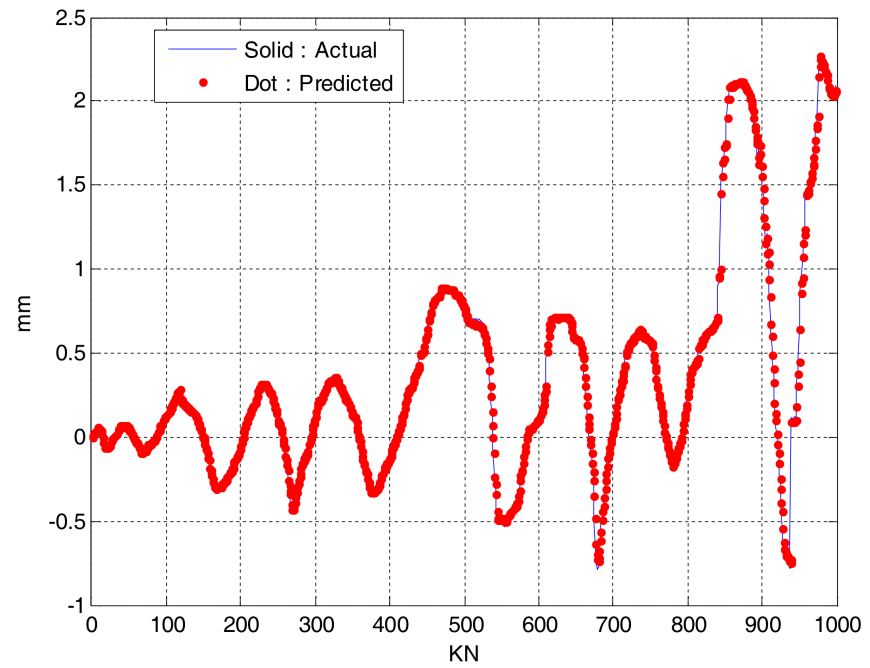

Figure 8. Training for no-fines lightweight concrete wall without the horizontal reinforcement.

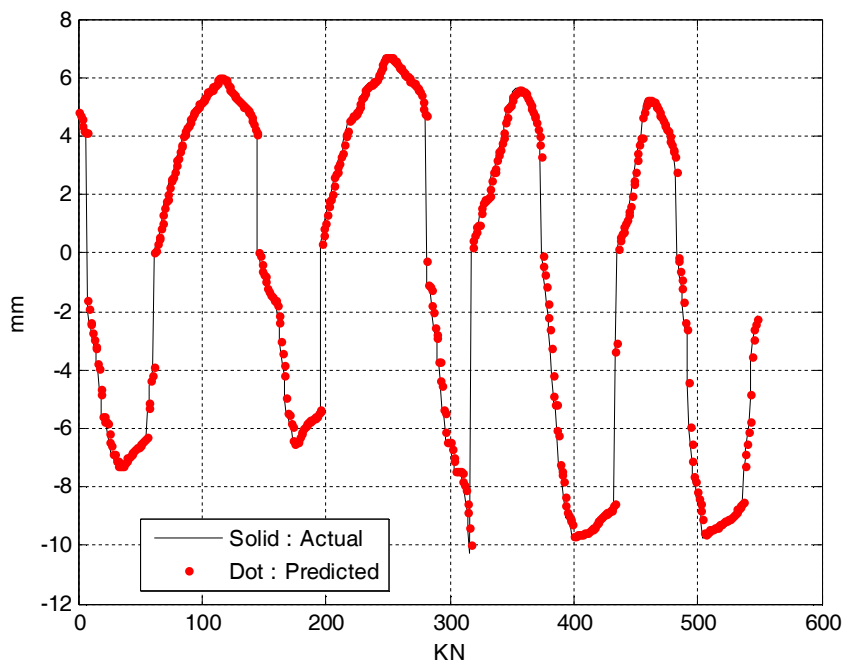

Figure 9. Validation for no-fines lightweight concrete wall with the horizontal reinforcement.

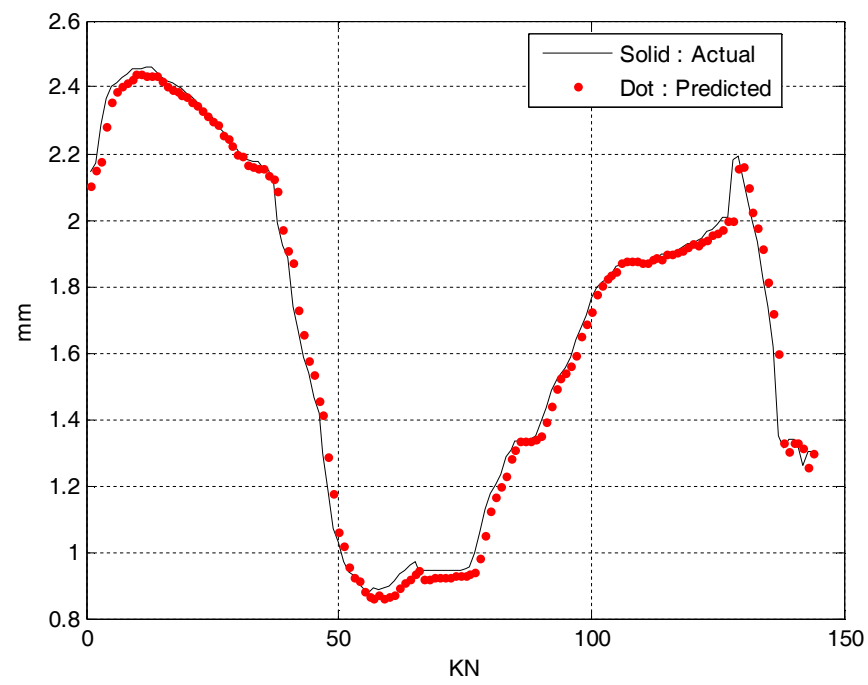

Figure 10. Validation for no-fines lightweight concrete wall without the horizontal reinforcement. 
The correlation coefficient $\mathrm{R}$ that shows at Equation (22) what proportion of the variation of the predicted values can be attributed to the linear relationship with the actual values is given by the formula:

$$
R=\frac{S_{x y}}{\sqrt{S_{x x} \times S_{y y}}}
$$

The experimental deflection of the no-fines lightweight concrete wall due to cyclic load is illustrated in Figures 11 and 12. The correlation coefficients are 0.9927 for deflection of no-fines lightweight concrete wall with reinforcement and 0.9955 for deflection of no-fines lightweight concrete wall without reinforcement which was distributed evenly on both sides of the line, which indicates an excellent performance of the model.

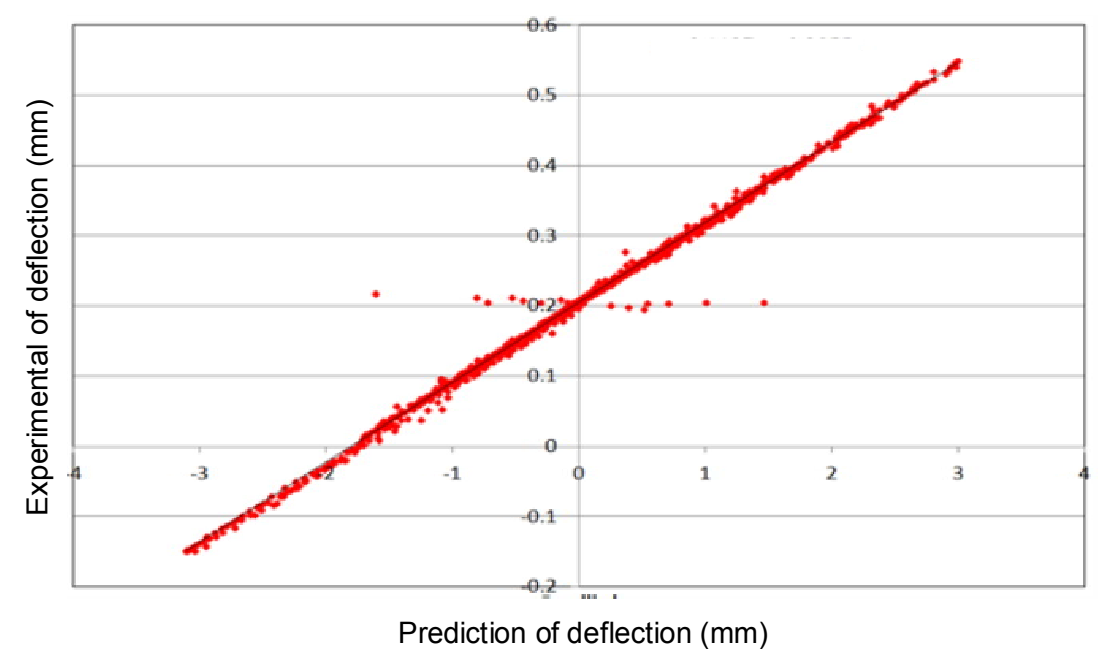

Figure 11. Predicting the accuracy of neural-network system for no-fines lightweight concrete wall with the horizontal reinforcement.

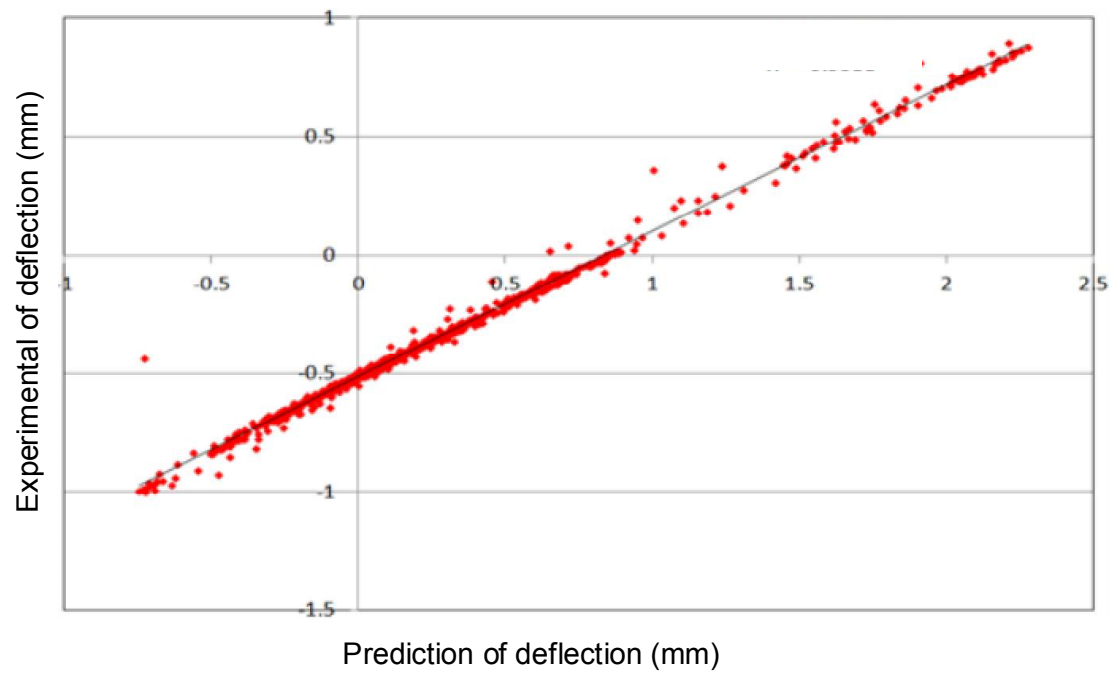

Figure 12. Predicting the accuracy of neural-network system for no-fines lightweight concrete wall without the horizontal reinforcement.

\section{Conclusions}

The development of a model using ANN to predict the deflection due to the dynamic force in no-fines lightweight concrete wall comprising 2 input variables and 1 output variable has been presented in this paper. The model structure was referred to as perceptron multilayer. In general, 
the neural network is designed to be able to anticipate the nonlinear and complex interactions between input/output variables and no-fines lightweight concrete wall. Therefore, the ANN model can be used as an alternative model to predict the deformation more accurately, simply and quickly due to the alternating horizontal loads on a no-fines lightweight concrete wall.

Author Contributions: Ridho Bayuaji conducted preparing and maintaining facility test conditions, the collection data, data analysis and wrote the paper. Totok Ruki Biyanto conducted the neural network modelling and carried out data analysis.

Acknowledgments: The author thank to Ministry of Research, Technology and Higher Education of the Republic of Indonesia and LPPM ITS for funded this research and publication.

Conflicts of Interest: The authors declare no conflict of interest.

\section{References}

1. Bousabbah, L.; Bruneau, M. Review of the Seismic Performance of Unreinforced Masonry Wall. In Proceedings of the 10th World Conference on Earthquake Engineering, Madrid, Spain, 19-24 July 1992; pp. 4537-4540.

2. Calderón, S.; Sandoval, C.; Arnau, O. Shear Response of Partially-Grouted Reinforced Masonry Walls with a Central Opening: Testing and Detailed Micro-Modelling. Mater. Des. 2017, 118, 122-137. [CrossRef]

3. Salmanpour, A.H.; Mojsilović, N.; Schwartz, J. Displacement Capacity of Contemporary Unreinforced Masonry Walls: An Experimental Study. Eng. Struct. 2015, 89, 1-16. [CrossRef]

4. European-Standard-En1996-1-1. Euro Code 6: Design of Masonry Structures; Comité Européen de Normalisation: Brussels, Belgium, 2005.

5. Bourzam, A.; Goto, T.; Miyajima, M. Shear Capacity Prediction of Confined Masonry Walls Subjected To Cyclic Lateral Loading. Doboku Gakkai Ronbunshuu A 2008, 25, 47-59.

6. Bayuaji, R.; Biyanto, T.R. Model Jaringan Saraf Tiruan Kuat Tekan Beton Porus Dengan Material Pengisi Pasir. J. Civ. Eng. 2013, 20, 23-32.

7. Nuruddin, M.; Diah, A.; Biyanto, T.; Darmawan, M.S.; Bayuaji, R. Concrete Structures Life Span Based on Carbonation Rate Using Artificial Neural Network. J. Aplikasi 2011, 9, 41-47. [CrossRef]

8. Mardiyono, M.; Suryanita, R.; Adnan, A. Intelligent Monitoring System on Prediction of Building Damage Index Using Neural-Network. Telecommun. Comput. Electron. Cont. 2012, 10, 155-164. [CrossRef]

9. Xiaoping, Y.; Wenhui, Z.; Yamin, F. Neural Network Adaptive Control for X-Y Position Platform with Uncertainty. Telkomnika 2014, 12, 79-86. [CrossRef]

10. Murray, R.; Neumerkel, D.; Sbarbaro, D. Neural Networks for Modeling and Control of a Non-Linear Dynamic System. In Proceedings of the 1992 IEEE International Symposium on Intelligent Control, Glasgow, Scotland, 11-13 August 1992; pp. 404-409.

11. Cybenko, G. Approximation by Superpositions of a Sigmoidal Function. Math. Cont. Signal Syst. 1989, 2, 303-314. [CrossRef]

12. Norgaard, M.; Ravn, O.; Poulsen, N.K.; Hansen, L.K. Neural Network for Modelling and Control of Dynamic Systems; Springer: New York, NY, USA, 1999. 